\title{
Zona pellucida antibodies in human sera
}

\author{
P. L. Nayudu, L. E. Freemann and A. O. Trounson \\ Department of Obstetrics \& Gynaecology, Monash University, Queen Victoria Medical Centre, \\ 172 Lonsdale Street, Melbourne 3000, Victoria, Australia
}

\begin{abstract}
Summary. A quantitative indirect immunofluorescent assay developed for the measurement of antibodies produced in rabbits against porcine zonae pellucidae was modified and used to detect autoantibodies specific to human zonae pellucidae. An undetermined number of human serum constituents which appear to vary quantitatively between individuals had the capacity to bind non-specifically the porcine zonae used as antigen in this assay. Binding was reduced or eliminated by altering the chemical composition of the assay system until the only positive results were for sera from infertile, sub-fertile and menopausal women. These positive sera were adsorbed with washed porcine blood cells, spleen cells, and liver cells. Each tissue completely removed the positive binding to porcine zonae. The positive sera were also tested against human oocytes with and without porcine tissue adsorption, and no positive fluorescence was detected. It is therefore unlikely that the antibodies in human sera which bind to porcine zonae pellucidae could be a causal factor in infertility in women.
\end{abstract}

\section{Introduction}

The zona pellucida (zona) is the extracellular matrix surrounding the mammalian oocyte, and has a significant role in fertilization (Gwatkin, 1976). Although not fully analysed, information is accumulating on its carbohydrate and protein composition (Bleil \& Wassarman, 1980; Dunbar, Wardrip \& Hedrick, 1980). The zona has also been shown to be antigenic and the antibodies produced against it to cause sterility in females of homologous or closely related species (Shivers, Dudkiewicz, Franklin \& Russell, 1972; Gwatkin, Williams \& Carlo, 1977; Gwatkin \& Williams, 1978; Tsunoda \& Chang, 1978a, b; Sacco, 1979).

Evidence for the possible spontaneous production of autoantibodies to the zona pellucida with age in mice has been presented by Tsunoda \& Chang (1979). The functional indicator used was inhibition of in-vitro fertilization in the presence of sera from female mice which had ceased to breed. In women with unexplained infertility or in menopausal women autoimmunity to the zona is an interesting possibility, and would have obvious clinical significance as a causal factor in blocking fertilization. However, attempts to study the question have been impeded by technical problems such as the lack of a specific quantitative assay. All studies have used indirect immunofluorescence to detect antibody binding to zonae from pigs and sometimes women, but the methods of removing non-specific binding serum molecules differed and so did the conclusions.

In their initial study with human sera, Shivers \& Dunbar (1977) claimed that a zona-specific antibody was detected in a high proportion of the samples from infertile women (WHO serum bank) and not in the controls. Sacco (1978) confirmed that an antibody was involved when he 
purified the immunoglobulin fraction from a zona-positive WHO serum sample, and found that it bound to porcine zona, even when degraded into $F\left(a b^{\prime}\right)$ fragments. However, Sacco \& Moghissi (1979) later reported that antibodies to the zona pellucida were widespread among samples of serum from fertile and infertile humans, thereby casting doubt on their significance in infertility. Mori et al. $(1978,1979)$ described an adsorption method using fixed erythrocytes from the same species as the test oocyte, designed to eliminate haemagglutinins that were not zona specific. After adsorption, immunofluorescence against both porcine and human zonae was largely confined to a proportion of sera from infertile women.

The present work differs from previous studies of human zona autoantibodies in several ways. We attempted to develop an assay which would be specific for zona antibodies in human serum without the necessity of preadsorption. To that aim, the quantitative immunofluorescent assay, developed with heteroimmune antisera raised in rabbits against porcine zonae pellucidae (Nayudu, Freemann \& Trounson, 1982), was modified to test human sera.

\section{Materials and Methods}

\section{Oocyte collection}

Porcine oocytes were obtained from the slaughterhouse and processed as described by Nayudu et al. (1982). Human oocytes were collected from ovarian wedges, obtained during surgical procedures for removal of ovarian cysts.

\section{Human sera}

Human sera were obtained from artificial insemination and infertility clinics (Melbourne Family Medical Centre, Queen Victoria Medical Centre, Prince Henry's Hospital, Royal Women's Hospital in Melbourne). The sera were stored untreated at $-20^{\circ} \mathrm{C}$ until they were tested.

The 400 samples used in these tests were 112 women with idiopathic infertility, 20 women infertile with known cause, 83 fertile women, 55 sub-fertile women, 50 menopausal but previously fertile women and 80 fertile and infertile men.

Women and men were classified as infertile, subfertile or fertile according to their medical history. For women, the categories were defined as: (1) infertile, not having conceived after at least 3 years of unprotected coitus with a fertile man or regular artificial insemination; (2) subfertile, having conceived once with a history of difficulty of at least 2 years duration in achieving a subsequent conception, (3) fertile, term pregnancies being achieved without difficulty. For men, those infertile were oligospermic or azoospermic. Fertile men were proven donors from an artificial insemination clinic. For testing purposes, both types of infertile females were treated as a single group. Infertile and fertile males were also treated as a single group.

\section{The indirect immunofluorescence assay}

The diluent for the sera and wash buffer was phosphate-buffered saline ( 274 mosmol, pH 7.4 ) to which was added $0.05 \mathrm{M}$-sucrose and $1 \%$ sodium azide. The antibody binding proteins tested, all fluorescein-isothiocyanate (FITC) labelled, were: (1) purified rabbit IgG anti-human IgG (Nordic Immunological Laboratories, Tilburg, The Netherlands), (2) rabbit anti-human globulin (Commonwealth Serum Laboratories, Melbourne, Victoria, Australia), (3) goat anti-human globulin preadsorbed with sheep liver powder and rat gastrointestinal tract, liver and kidney homogenate (Monash University Pathology Department, Melbourne, Australia), (4) goat anti-human IgG (Kallestad Laboratories, Austin, Texas, U.S.A.) and (5) Protein A (Pharmacia Fine Chemicals, North Ryde, New South Wales, Australia). 
As a test for specificity, the four FITC-labelled second antibodies were adsorbed with untreated porcine oocytes. The oocytes were subsequently viewed using the microscopic conditions described below. Only the anti-human IgG from Nordic and the anti-human globulin from Monash University did not bind to the untreated zonae or oocytes. Of these two, when used at equal dilutions after the oocytes had been incubated with zona-positive sera, Nordic anti-human IgG produced more intense fluorescence and was therefore chosen for routine use. As a further test of specificity, Nordic anti-human IgG was adsorbed with excess human IgG and then assayed against porcine zonae pretreated with zona-positive human serum. The lack of fluorescence indicated specific binding of the anti-IgG to IgG. Protein A-FITC also produced a fluorescent ring when bound to zonae which had been pretreated with zona-positive human serum, but it was at too low an intensity to be useful.

The procedure adopted for use with human sera was as follows. The sera were precoded by a person other than the assayist. In the early stages of the optimization (A and B), and in Stage E a random sample of 20 sera at each stage were diluted $1: 2,1: 5$ and $1: 10$. Optimal dilution was at $1: 10$ because greater protein concentrations tended to inhibit the fluorescent ring. The sera were heat-inactivated for $35 \mathrm{~min}$ at $56^{\circ} \mathrm{C}$. The effect of heat inactivation after dilution did not differ from that performed before. The assay, involving $200 \mu$ diluted serum and 20 porcine oocytes was carried out as described by Nayudu et al. (1982) over 3 days. Six oocytes were randomly chosen for measurement. The sequential incubations and washes of the oocytes were human serum $\left(16 \mathrm{~h}\right.$ at $\left.4^{\circ} \mathrm{C}\right)$, excess buffer ( $4 \mathrm{~h}$ at room temperature), FITC anti-human IgG ( $4 \mathrm{~h}$ at room temperature) and excess buffer $\left(16 \mathrm{~h}\right.$ at $\left.4^{\circ} \mathrm{C}\right)$.

The fluorescence standard was the rabbit antiserum to pig zonae, produced by injection of intact oocytes and preadsorbed with porcine tissues to increase zona specificity as described by Nayudu et al. (1982) and it was included with each assay at a dilution of $1: 200$. Three human sera were assayed in duplicate as a reliability control for each set of samples. A positive zona antibody reaction was shown by a fluorescent ring at the outer surface of the zona. No ring indicated a negative reaction. Fluorescence in other parts of the oocyte was considered to be contributed by non-specific factors.

Zona fluorescence was detected and photographed on a Leitz Orthoplan 2 with Ploemopak fluorescent filter set $\mathbf{D}$ with an emission range of u.v. to violet. The fluorescence was detected by a photomultiplier and measured by a digital volt meter as described by Nayudu et al. (1982).

\section{Adsorptions}

Sera were adsorbed after heat inactivation with an equal packed volume of (1) washed human Type $O$ or porcine erythrocytes from 3 pigs to eliminate possible variation due to individual blood types, (2) washed porcine spleen cells and (3) washed porcine liver cells, for $1 \mathrm{~h}$ at room temperature with occasional mixing. The tissue cells were prepared by glass homogenization in PBS at $4^{\circ} \mathrm{C}$. All cells were washed and centrifuged 4 times in a 20 times volume of cold PBS (Nairn, 1976). The human Type O erythrocytes were used as a control for non-specific adsorption. This might be expected to be a significant factor in sera of low antibody titre, but only slight fluorescence reduction was observed.

\section{Haemagglutination}

Haemagglutination titration of sera was carried out using 5\% paraformaldehyde-fixed and washed porcine erythrocytes (Mori et al., 1979) and fresh washed porcine erythrocytes. Sera were diluted in PBS alone or with test substances. 


\section{Results}

The initial trials to detect zona antibody in human sera used a method adapted from the rabbit anti-porcine zona assay. No sucrose or sodium azide was used in the buffer, the sera were not heat inactivated, and FITC anti-human globulin was used as the second antibody. Irregular or generalized fluorescence was observed with all categories of sera (Plate 1). Text-figure 1(A) shows the percentage of each type of sera which produced fluorescence under these conditions. These results suggested that false positive reactions were being detected. The assay conditions were subsequently modified to eliminate the suspected non-specific fluorescence. Each factor of the assay conditions altered (Text-fig. 1) had a cumulative effect. In each succeeding level, for all serum categories, the number of samples detected as positive was reduced, and no previously undetected positive sera appeared.

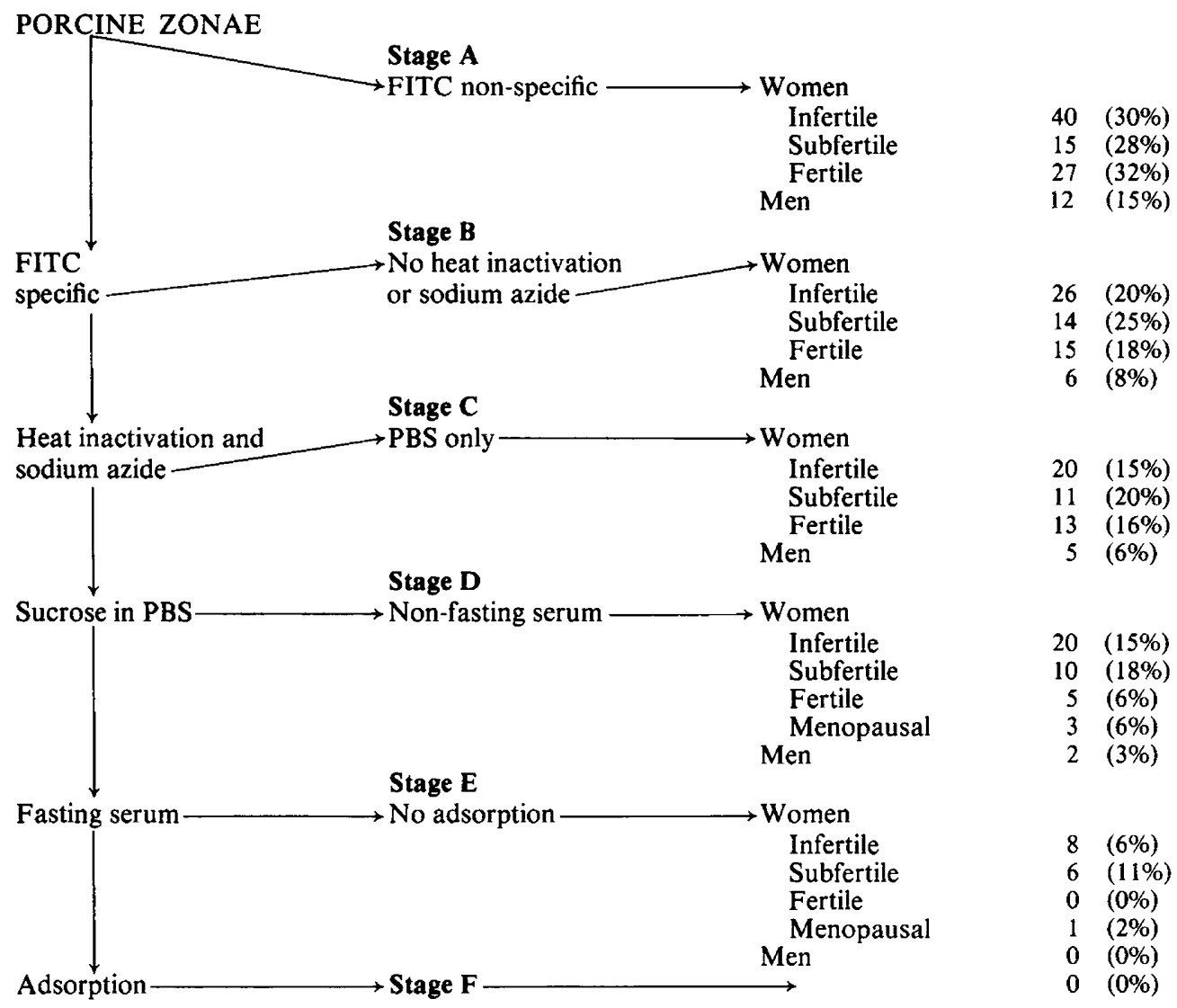

Text-fig. 1. Flow diagram of the cumulative effects of assay optimizations. Menopausal women were tested for the first time at stage $D$. The total numbers of patients tested were 132 infertile women, 55 sub-fertile women, 83 fertile women, 50 menopausal women and 80 men.

The use of a second antibody specific to human IgG rather than to human immunoglobulins was the initial step in reducing the generality of fluorescence (Text-fig. 1B). To ensure oocyte preservation, heat inactivation of the sera and sodium azide in the assay buffer were used (Text-fig. 1C). The fluorescence remaining after this treatment was more regular and specific to the surface of the zona. The presence of sucrose (Text-fig. 1D) in the buffer further reduced the positives, particularly for sera from fertile women and men. A test between sera from fasting and 
non-fasting patients (Text-fig. 1E) showed a further proportion of the remaining positives to be entirely or partly (some were reduced in intensity) due to components of the sera present during non-fasting.

Under these conditions the positive results were confined to infertile, subfertile and menopausal women. The appearance of fluorescence on the zonae was uniform and confined to the outer surface. Plate 2, Figs 6 and 7 illustrate two intensities of fluorescence.

The haemagglutination titres (Table 1) of zona-positive and -negative sera, as assayed under preadsorption optimal conditions (Text-fig. 1E), were tested using formalin-fixed and fresh porcine erythrocytes with serum diluted in PBS or PBS plus sucrose. There was no difference in the range of haemagglutination titres with fixed erythrocytes $(1: 2$ to $1: 256)$ between sera from infertile or subfertile zona-positive and fertile and infertile zona-negative patients. In addition, all haemagglutination titres were greater than $1: 256$ with fresh erythrocytes. However, the presence of sucrose reduced haemagglutination with fixed erythrocytes in 4 out of 14 samples. For these same samples, sucrose reduced fluorescence for 2 positive sera and eliminated fluorescence in 2 other sera which were apparently positive in PBS alone.

Table 1. The effect of sucrose on zona fluorescence and haemagglutination titres* of porcine zona-positive and -negative human sera

\begin{tabular}{lllll}
\hline \multicolumn{2}{c}{ Zona fluorescence } & & \multicolumn{2}{c}{$\begin{array}{c}\text { Haemagglutination titre } \\
\text { (fixed erythrocytes) }\end{array}$} \\
\cline { 1 - 2 } PBS & Sucrose & & PBS & Sucrose \\
\hline Yes & No change & & $1: 8$ & $1: 8$ \\
Yes & No change & & $1: 16$ & $1: 16$ \\
Yes & No change & & 0 & 0 \\
Yes & Reduction & & $1: 32$ & $1: 8$ \\
Yes & No change & & $1: 256$ & $1: 256$ \\
Yes & No change & & $1: 2$ & $1: 2$ \\
Yes & Reduction & & $1: 128$ & $1: 16$ \\
No & No & & $1: 4$ & $1: 4$ \\
No & No & $1: 128$ & $1: 128$ \\
No & No & $1: 16$ & $1: 16$ \\
Yes & No & $1: 32$ & $1: 2$ \\
No & No & $1: 2$ & $1: 2$ \\
Yes & No & $1: 256$ & $1: 32$ \\
No & No & $1: 8$ & $1: 8$ \\
\hline
\end{tabular}

* Haemagglutination titres using fresh erythrocytes were in excess of $1: 256$.

Human sera, positive under optimal assay conditions for zona antibodies, were adsorbed with porcine liver, spleen, and erythrocytes. This treatment removed all detectable porcine zona-binding capacity (Text-fig. 1F). The appearance of the oocytes was identical to that of preadsorption negative oocytes (Pl. 2, Fig. 8). Because of this result the quantitation of fluorescence under optimal preadsorption conditions is not reported. Serum haemagglutination capacity was not tested after adsorption because there was no correlation of haemagglutination with positive zona reaction. When non-adsorbed sera, positive with porcine zonae, were tested with human zonae under the same assay conditions, no reaction could be detected.

\section{Discussion}

The use of porcine zonae pellucidae to test for human zona autoantibodies was based on evidence of human and porcine zona antigenic cross-reactivity presented by Shivers \& Dudkiewicz (1974) and Sacco (1977). Their work indicated a low to moderate level of 
porcine-human zona antigenic similarity. The inhibition of in-vitro human sperm binding to human oocytes by antiporcine zona/ovary sera, described by Inoue, Fujii \& Kami (1979) and Trounson, Shivers, McMaster \& Lopata (1980) provided further evidence. However, the precise nature or degree of the similarity is still in question because of the heterogeneity of the antisera used and the lack of knowledge of the molecular composition of the zonae in the two species.

Non-specific binding of serum molecules to the zona in an assay system has been a more obvious problem with human sera than with heteroantisera produced in animals, due largely to the minimal serum dilutions necessary to detect low antibody concentrations. Because the zona contains many anionic groups (Yanagimachi, Nicholson, Noda \& Fujimoto, 1973) which have the tendency, in general, to bind a variety of molecules (Lindahl \& Höök, 1978), difficulties in the assay of specific antibody binding would be expected.

Sucrose was included in this assay system because it prevented the zona 'stickiness', and was found to be beneficial in the assay for rabbit anti-porcine zona antibody (Nayudu et al., 1982). Its effect with zona-binding human sera was variable. When sucrose reduced or eliminated fluorescence, haemagglutination titres with fixed porcine erythrocytes were also reduced. However, haemagglutinating capacity of the human sera was not confined to the zona-positive samples. This shows that a proportion of erythrocyte-binding molecules do not bind zona pellucida.

Fasting was a further significant factor in the reduction of false positives, and general background fluorescence, possibly due to reduction of circulating glyco- or lipoproteins which would be likely to bind non-specifically to zonae.

Under optimal preadsorption conditions, positive reactions only occurred in idiopathic infertile, subfertile, and menopausal women. The percentage detected and the titre (all detectable at $1: 10$ dilution) were consistent with the results of Mori et al. $(1978,1979)$ and Nishimoto, Mori, Yamada \& Nishimura (1980), suggesting that the present assay was detecting zona antibodies with adequate sensitivity. However, in contrast to previous reports, when the assay results were tested for specificity by preadsorption of the sera with fresh porcine liver, spleen or erythrocytes, all porcine zona-binding capacity of the sera was removed. Sacco \& Moghissi (1979) described a variable but unquantified response to adsorption with human tissue. Mori et al. $(1978,1979)$ found porcine zona-positive sera mainly confined to infertile women after adsorption with fixed porcine erythrocytes. The difference is likely to be due to differences in the assay specificity and the greater effectiveness of fresh tissue over fixed as an immunoadsorbent (Nairn, 1976).

\section{PLATE 1}

Examples of results obtained with suboptimal assay conditions for antibody detection on porcine zonae. All these results occurred at stages A-D (see Text-fig. 1) but were more frequent at earlier stages.

Fig. 1. Irregular fluorescent ring.

Fig. 2. General zona fluorescence.

Fig. 3. General background fluorescence in oocyte and zona with fluorescent ring.

Fig. 4. Strong positive, irregular fluorescent coating exposing patch of faint ring on zona surface.

Fig. 5. Two oocytes showing inconsistent fluorescence with some background.

\section{PLATE 2}

Examples of fluorescence obtained using optimal assay conditions (stage E) for detection of antibodies on pig zonae. The sera were from 3 infertile women.

Fig. 6. Strong positive fluorescence.

Fig. 7. Weak positive fluorescence.

Fig. 8. Negative, no fluorescence. 
PLATE 1
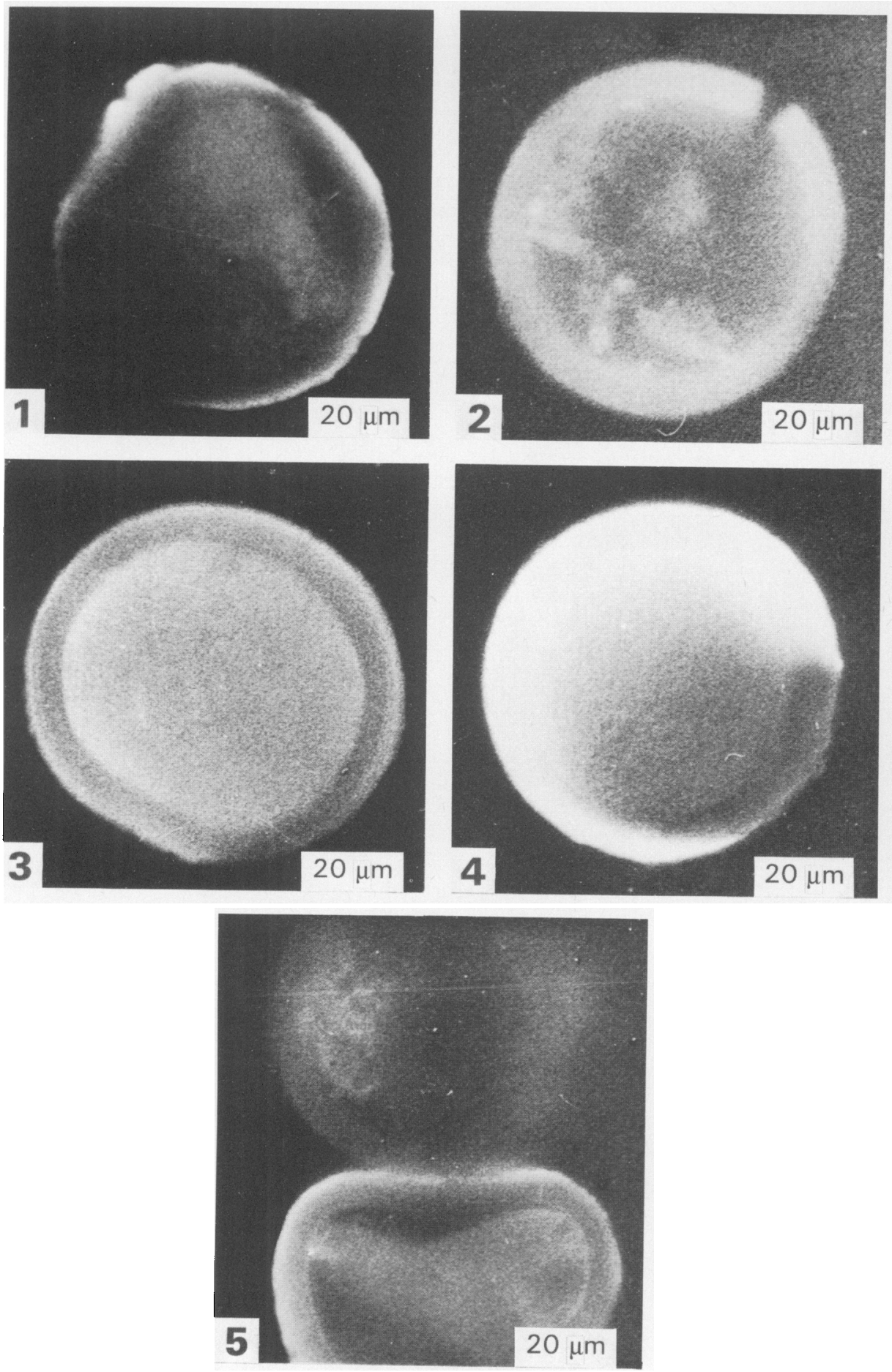

(Facing p. 82) 
PLATE 2
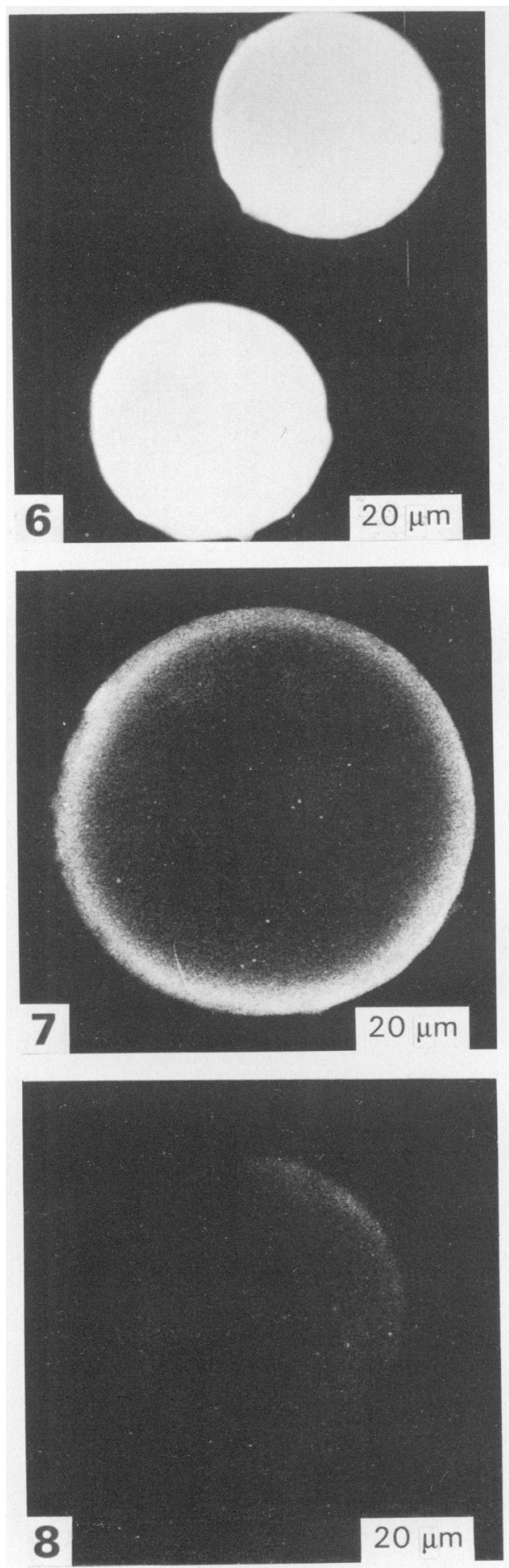
The lack of binding to human zonae pellucidae by sera possessing porcine zona-binding capacity differs from the results of Mori et al. $(1978,1979)$ and Nishimoto et al. (1980) who reported that sera which bound human zonae after adsorption with human $\mathrm{AB}$ erythrocytes were identical to those which bound porcine zonae after adsorption with porcine erythrocytes. However, our results are in line with those of Sacco \& Moghissi (1979), who reported that of 11 porcine zona-positive sera, 1 was moderately positive, 3 were weakly positive, and 7 were negative when tested on human ova. Clinical corroboration is provided by Bleau, Bousquet, Roberts, Chapdelaine \& Faucher (1980) who reported the serum of an infertile woman as positive for zona antibodies when tested with porcine zonae but negative with human zonae.

Since human antibodies which react with porcine antigens are known to occur in man (McKenzie, Stocker, Ting \& Morris, 1968), a possible explanation of the results reported here is that there is correlation of porcine antibody with a small proportion of infertile women, but that it is not a primary cause of infertility. An additional explanation could be that the degree of antigenic similarity between porcine and human zonae is actually much less than previously suggested. Therefore, human immunoglobulin reactive with porcine cells, including the zona, would have less affinity for the human zona than for the porcine zona.

In conclusion, this study has shown that no zona specific antibodies were detectable by immunofluorescence of porcine zonae pellucidae incubated with sera from infertile or fertile men and women when precautions to reduce non-specific binding were taken. Under these conditions human zonae were not bound by antibody. It is therefore unlikely that the antibodies detected in human sera, with the capacity to bind to porcine zona, are a causal factor in infertility in man.

We thank the co-operating medical clinics for the supply of human sera for this study and $\mathrm{Dr}$ B. Roberts for the access to the Leitz fluorescent microscope. The International Planned Parenthood Federation supplied a part-time salary for L.E.F. and partly supported the project. P.L.N. is a Senior Research Officer of the National Health and Medical Research Council of Australia.

\section{References}

Bleau, G., Bousquet, D., Roberts, K.D., Chapdelaine, A. \& Faucher, G. (1980) Anti-gamete antibodies in both partners of an infertile couple. Fert. Steril. 34, 198, Abstr.

Bleil, J.D. \& Wassarman, P.M. (1980) Structure and function of the zona pellucida: identification and characterization of the proteins of the mouse oocyte's zona pellucida. Devl Biol. 76, 189-202.

Dunbar, B.S., Wardrip, N.J. \& Hedrick, J.L. (1980) Isolation, physiochemical properties and the macromolecular composition of the zona pellucida from porcine oocytes. Biochemistry, N.Y. 19, 356365 .

Gwatkin, R.B.L. (1976) Fertilization. In The Cell Surface in Animal Embryogenesis and Development, pp. 1-54. Eds G. Poste \& G. L. Nicholson. Elsevier/North Holland, Amsterdam.

Gwatkin, R.B.L. \& Wiiliams, D.T. (1978) Immunization of female rabbits with heat solubilized bovine zonae: production of anti-zona antibody and inhibition of fertility. Gamete Res. 1, 19-26.

Gwatkin, R.B.L., Williams, D.T. \& Carlo, D.J. (1977) Immunization of mice with heat-solubilized hamster zonae: production of anti-zona antibody and inhibition of fertility. Fert. Steril. 28, 871-877.
Inoue, M., Fujil, A. \& Kami, K. (1979) The effects of antibodies to human and pig ovaries on the human sperm-zona interaction. Acta obstet. gynaec. japon. 30, 1563-1564, Abstr.

Lindahl, U. \& Höök, M. (1978) Glycosaminoglycans and their binding to biological macromolecules. $A$. Rev. Biochem. 47, 385-417.

McKenzie, I.F.C., Stocker, J., Ting, A. \& Morris, P.J. (1968) Human lymphocytotoxic and haemagglutinating activity against sheep and pig cells. Lancet 1, 366-387.

Mori, T., Nishimoto, T., Kitagawa, M., Noda, Y., Nishimura, T. \& Oikawa, T. (1978) Possible presence of autoantibodies to zona pellucida in infertile women. Experientia 34, 797-799.

Mori, T., Nishimoto, T., Kohda, H., Takai, I., Nishimura, T. \& Oikawa, T. (1979) A method for specific detection of auto-antibodies to the zona pellucida in infertile women. Fert. Steril. 32, 67-72.

Nairn, R.C. (1976) Fluorescent Protein Tracing, 4th edn. Churchill Livingstone, Edinburgh.

Nayudu, P.L., Freemann, L.E. \& Trounson, A.O. (1982) A quantitative indirect immunofluorescent assay for zona pellucida antibodies. J. Reprod. Fert. 65, 67-75.

Nishimoto, T., Mori, T., Yamada, I. \& Nishimura, T. 
(1980) Autoantibodies to zona pellucida in infertile and aged women. Fert. Steril. 34, 552-556.

Sacco, A.G. (1977) Antigenic cross-reactivity between human and pig zona pellucida. Biol. Reprod. 16, 164-173.

Sacco, A.G. (1978) Immunological specificity of antizona binding to zona pellucida. J. exp. Zool. 204, 181-186.

Sacco, A.G. (1979) Inhibition of fertility in mice by passive immunization with antibodies to isolated zonae pellucidae. J. Reprod. Fert. 56, 533-537.

Sacco, A.G. \& Moghissi, K.S. (1979) Anti-zona pellucida activity in human sera. Fert. Steril. 31, 503-506.

Shivers, C.A. \& Dudkiewicz, A.B. (1974) Inhibition of fertilization with specific antibodies. In Physiology and Genetics of Reproduction, Part B, pp. 81-96. Eds E. M. Coutinho \& F. Fuchs. Plenum Press, New York.

Shivers, C.A. \& Dunbar, B.S. (1977) Auto-antibodies to zona pellucida: a possible cause for infertility in women. Science, N.Y. 197, 1082-1084.

Shivers, C.A., Dudkiewicz, A.B., Franklin, L.E. \&
Russell, E.N. (1972) Inhibition of sperm-egg interaction by specific antibody. Science, N.Y. 178, 1211.

Trounson, A.O., Shivers, C.A., MeMaster, R. \& Lopata, A. (1980) Inhibition of sperm binding and fertilization of human ova by antibody to porcine zona pellucida \& human sera. Arch. Androl. 4, 29-36.

Tsunoda, T. \& Chang, M.C. (1978a) Effect of antisera against eggs and zona pellucida on fertilization and development of mouse eggs in vivo and in culture. $J$. Reprod. Fert. 54, 233-237.

Tsunoda, T. \& Chang, M.C. (1978b) Effects of antisera on fertilization of mouse, rat and hamster eggs. Biol. Reprod. 18, 468-474.

Tsunoda, T. \& Chang, M.C. (1979) The suppressive effect of sera from old female mice on in vitro fertilization and blastocyst development. Biol. Reprod. 20, 355-361.

Yanagimachi, R., Nicholson, G.L., Noda, Y.D. \& Fujimoto, M. (1973) Electron microscopic observations of the distribution of acidic animal residues on hamster spermatozoa and eggs before and during fertilization. J. Ultrastruct. Res. 43, 344-353.

Received 12 June 1981 